\title{
A COMPREENSÃO DA ORDEM ECONÔMICA A PARTIR DA VALORIZAÇÃO DO TRABALHO HUMANO: UMA ANÁLISE BASEADA NA PROTEÇÃO À SAỬE DO TRABALHADOR
}

\author{
THE COMPREHENSION OF ECONOMIC ORDER FROM THE VALORIZATIONOF \\ HUMAN WORK: AN ANALYSIS BASED ON WORKER HEALTH PROTECTION
}

\author{
Eduardo Milléo Baracat ${ }^{1}$ \\ Priscila Luciene Santos de Lima ${ }^{2}$ \\ Jayne Letycia Stockmanns ${ }^{3}$ \\ Hélcio Kronberg ${ }^{4}$
}

\begin{abstract}
RESUMO
O presente artigo analisa a importância da proteção da saúde do trabalhador na construção da ordem econômica prevista constitucionalmente, especialmente calcada na valorização do trabalho humano, na defesa do meio ambiente e na dignidade da pessoa humana. Nesse sentido, apresenta a estrutura da ordem econômica que se encontra disposta na Constituição e realiza uma abordagem dialética entre a concepção material e humanizada de trabalho. Analisa, ainda, de maneira reflexiva, a partir da estrutura da ordem econômica e do real sentido e significado do trabalho para o indivíduo, a proteção da saúde do trabalhador enquanto fundamento da valorização do trabalho humano, que é o elemento legitimador preponderante ao desenvolvimento econômico e social do país.
\end{abstract}

Palavras-chave: Ordem Econômica Constitucional; valorização do trabalho humano; proteção da saúde do trabalhador.

\footnotetext{
ABSTRACT

This article aims to demonstrate the importance of protecting workers' health in the construction of the constitutionally provided economic order, especially based on the valorization of human work, defense of the environment and the dignity of the human person. In this sense, there is a need to present the structure of the economic order found in the Constitution, perform a

1 Doutor em Direito das Relações Sociais pela Universidade Federal do Paraná. Mestre em Direito Privado pela Universidade Federal do Paraná. Diplôme Supérieur de 1'Université - Droit du Travail \& Sécurité Sociale pela Université Panthéon-Assas/Paris II. Juiz Titular da $9^{a}$ Vara do Trabalho de Curitiba. Professor Permanente do Programa de Doutorado e Mestrado em Direito Empresarial e Cidadania do UNICURITIBA. Realizou estágio PósDoutoral na Universidade de Coimbra.

${ }^{2}$ Doutoranda em Direito Político e Econômico pela Universidade Presbiteriana Mackenzie - UPM. Mestre em Direito Empresarial e Cidadania pelo Centro Universitário Curitiba - UNICURITIBA. Especialista em Direito do Trabalho e Processual do Trabalho pela Pontifícia Universidade Católica do Paraná-PUCPR. Advogada e Professora Universitária.

${ }^{3}$ Mestranda em Direito Empresarial e Cidadania pelo Centro Universitário Curitiba - UNICURITIBA. Especialista em Direito e Processo do Trabalho pela Universidade Estácio de Sá. Advogada.

${ }^{4}$ Investigador, membro dos grupos de pesquisa Cidadania Empresarial no Século XXI - UNICURITIBA - Brasil, e integrante do grupo de Pesquisa Internacional - REDTH (Rede de Estudos em Direitos Humanos e Transnacionalidade)
} 
dialectical approach between the material and humanized conception of work, as well as and, finally, from the structure of the economic order and of the real sense and meaning of work for the individual, to reflectively analyze the protection of workers' health as a basis for the valorization of human work, which is the predominant legitimizing element to the country's economic and social development. For the development of the research, the deductive-dialectic method will be employed, through the use of a bibliographic reference.

Key-words: Constitutional Economic Order; valorization of human work; protection of worker health.

\section{INTRODUÇÃO}

As novas organizações de trabalho, marcadas por constantes avanços tecnológicos, demonstram-se cada vez mais preocupadas com o desenvolvimento da alta produtividade, a redução de custos e a conquista crescente do lucro.

Neste contexto, visualiza-se um panorama marcado pela precariedade das condições de trabalho e, por consequência, de evidentes prejuízos a integridade física e mental dos trabalhadores.

Ocorre que, não é neste cenário que se constrói a Ordem Econômica prevista constitucionalmente, isso porque o valor preponderante de sua estrutura se encontra fundamentado no trabalho humano, ou seja, concebido por sua valorização enquanto instrumento de realização e dignidade do trabalhador.

A partir disso, nesta conjuntura é que se apresenta a proteção da saúde do trabalhador e, portanto, a garantia de um meio ambiente de trabalho seguro e saudável, que possibilite ao trabalhador desempenhar suas atividades de maneira integral, em busca de sua identidade.

Nestas circunstâncias, instaura-se a problemática do presente estudo, que merece uma atenção especial, isso porque o trabalho não deve ser visualizado apenas como mecanismo de produção e lucro, mas também e, principalmente, como criador de sentimentos de satisfação, pertencimento e desenvolvimento pessoal do indivíduo.

Em vista disso, por intermédio do desenvolvimento desta pesquisa, será realizada uma abordagem da composição que permeia a Ordem Econômica, considerando, especialmente, a submissão da livre iniciativa a valorização do trabalho humano, em observância aos princípios da dignidade da pessoa humana, da defesa do meio ambiente e da função social da propriedade, esta última que fundamenta a função social da empresa enquanto proprietária dos meios de produção.

Em um segundo momento, em atenção ao principal aspecto circundante da Ordem Econômica, a valorização do trabalho humano, será realizada uma análise dialética entre a 
concepção material e humanizada de trabalho, isso porque a importância conferida pelos empregadores se destinam preponderantemente, senão completamente, a função técnica e material do trabalho.

A análise em questão leva em conta a concepção existente e àquela que é necessária e fundamental a compreensão do real significado de trabalho e da construção da Ordem Econômica Constitucional.

A partir disso, tendo como pressuposto a estrutura da Ordem Econômica edificada pela Constituição Federal, seu principal fundamento, consubstanciado pela valorização do trabalho humano e, por consequência, a concepção que se busca e se almeja de trabalho, passa-se a empreender uma análise ampla e reflexiva da importância da proteção da saúde do trabalhador como alicerce a garantia de um trabalho humanamente valorizado.

Desse modo e de maneira conclusiva, se objetiva, sem esgotamento do tema, que abriga inúmeras discussões, responder ao problema central da presente pesquisa, de maneira a determinar a fundamentalidade da proteção da saúde do trabalhador para se alcançar a valorização do trabalho humano, enquanto pressuposto da Ordem Econômica.

\section{A CONSTRUÇÃO CONSTITUCIONAL DA ORDEM ECONÔMICA}

A ordem econômica é estruturada constitucionalmente em fundamentos e princípios essenciais na construção do Estado Democrático de Direito, primando pela valorização do trabalho humano e pela dignidade da pessoa humana ao assegurar a livre iniciativa.

Tal se depreende da disposição contida no caput do art. 170 da Constituição Federal, o qual estabelece que "A ordem econômica, fundada na valorização do trabalho humano e na livre iniciativa, tem por fim assegurar a todos existência digna, conforme os ditames da justiça social [...]". (BRASIL, 1988)

A partir desta premissa, o mesmo dispositivo, em seus incisos, determina a observância dos princípios da "soberania nacional”, "propriedade privada", "função social da propriedade", "livre concorrência", "defesa do consumidor", "defesa do meio ambiente [...]”, "redução das desigualdades regionais e sociais", "busca do pleno emprego" e, "tratamento favorecido para as empresas de pequeno porte [...]”. (BRASIL, 1988)

Da mesma forma, tanto a livre iniciativa quanto a valorização do trabalho humano são elencados não apenas como fundamentos da ordem econômica, mas igualmente como princípios fundamentais do próprio Estado brasileiro, o que se visualiza do $\operatorname{artigo~} 1^{\circ}$ da 
Constituição Federal, o qual dispõe que "A República Federativa do Brasil [...] tem como fundamentos: [...] IV - os valores sociais do trabalho e da livre iniciativa". (BRASIL, 1988)

Na forma destacada por Pimenta e Prata (2009, p. 227), a ordem econômica não deve estar estruturada apenas nos princípios insculpidos no artigo 170 da Constituição Federal, mas também, calcada em seus fundamentos no sentido de formar uma "soberania social", que tenha capacidade de atender o exercício da cidadania e as exigências do capitalismo.

Nesse sentido, a ordem econômica encontra-se sistematizada por princípios que lhe são fundamentais na composição de um ordenamento prestigiado pelo desenvolvimento não apenas econômico, mas também e, principalmente, social.

Tais princípios, contudo, não concentram uma mesma utilidade, isso porque parte deles são determinantes ao funcionamento da ordem econômica, enquanto que os demais contemplam a finalidade que se pretende alcançar. Segundo Barroso (2001, p. 193-194),

\footnotetext{
O papel que a livre concorrência desempenha na ordem econômica é diverso daquele reservado ao princípio que propugna pela busca do pleno emprego ou pela redução das desigualdades regionais e sociais. À vista dessa constatação, é possível agrupar estes princípios em dois grandes grupos, conforme se trate de princípios de funcionamento da ordem econômica e de princípios-fins. Em linhas gerais, os princípios de funcionamento estabelecem os parâmetros de convivência básicos que os agentes da ordem econômica deverão observar. Os princípios fins, por sua vez, descrevem realidades materiais que o constituinte deseja sejam alcançadas.

$[\ldots]$

Os princípios de funcionamento referem-se à dinâmica das relações produtivas, às quais todos os seus agentes estão vinculados. Podem ser classificados como princípios de funcionamento aqueles referidos nos incisos I a VI do artigo 170, a saber (i) soberania nacional, (ii) propriedade privada, (iii) função social da propriedade, (iv) livre concorrência, (v) defesa do consumidor e (vi) defesa do meio ambiente.
}

Analisando-se cada um destes princípios, verifica-se que a soberania nacional traduz a independência econômica do Brasil em relação aos demais países, assim como, "do ponto de vista interno traduz a supremacia da Constituição e da lei, e da superioridade jurídica do Poder Público" (BARROSO, 2001, p. 194). A propriedade privada, por seu turno, reflete a liberdade da iniciativa privada "de apropriação [...] dos bens e meios de produção" (BARROSO, 2001, p. 194), que é a própria razão de ser do capitalismo, mas que se encontra relativizada pela função social da propriedade, princípio que determina a utilização da propriedade não voltada unicamente para fins econômicos, mas também para garantir a observância de interesses sociais.

Por sua vez, tem-se a livre concorrência como princípio sistematizante de uma ordem econômica livre não apenas para ingressar no mercado, mas também para nele permanecer, com vistas a garantir o funcionamento e a instrumentalização da livra iniciativa dos concorrentes. (GOMES, 2013, p. 9) 
No que se refere à defesa do consumidor e do meio ambiente, são também princípios limitantes a exploração econômica, destinados a resguardar os direitos sociais e fundamentais dos cidadãos, para que a atividade desenvolvida pelos agentes da economia não resultem na violação de direitos daquele que consome produtos e serviços e na depredação do meio ambiente.

Com relação ao princípio da redução das desigualdades regionais e sociais, tem-se o objetivo de uma atuação econômica preocupada com o equilíbrio social e financeiro entre toda população, mormente com vistas a assegurar a todos uma vida justa e digna, o que permeia igualmente o princípio da busca do pleno emprego, baseado no propósito de possibilitar a todos o acesso ao emprego e, garantir, assim, o desenvolvimento social do país.

E, o último princípio fundante da ordem econômica, compreende o favorecimento das empresas de pequeno porte em termos de tributos e previdência, por exemplo, a fim de que estas sejam fortalecidas e desenvolvam condições de competição de mercado com àquelas de grande porte, sobretudo pelo fato de serem elas as maiores garantidoras de emprego e renda no país.

A partir disso, verifica-se que "os princípios norteadores da ordem econômica constitucional demandam não só as práticas adotadas pela economia de mercado e pela livre iniciativa, mas também uma intervenção do Estado como agente disciplinador da economia". (PIMENTA; PRATA, 2009, p. 247)

Dessa forma, é evidente que "O Estado atua como agente regulador, normatizador e fiscalizador do domínio econômico, num jogo de equilíbrio de acordo com o ideal de liberdade de mercado, a dignidade da pessoa humana e os valores do trabalho" (PIMENTA; PRATA, 2009, p. 252)

Diante de todo o contexto compreendido pela ordem econômica, observa-se um caminho que deve ser percorrido pelo desenvolvimento econômico e social, o que depende da postura adotada pela classe empresarial.

É patente que a atuação empresarial deve se delinear de forma consciente, não apenas preocupada com a sua lucratividade, mas também com o alcance valorativo a que se revela o trabalho para seus empregados, que evidentemente não se cinge tão somente a busca pela sobrevivência. A empresa deve se visualizar igualmente como agente social.

Através desta concepção é que se deve construir o Estado Democrático de Direito, fundado na livre iniciativa, na valorização do trabalho humano e na dignidade da pessoa humana, isso porque é por estes princípios e fundamentos que deve ser igualmente construída e desenvolvida a estrutura empresarial. 
Feitas as considerações acerca da compreensão constitucional da ordem econômica em atenção aos seus princípios e fundamentos, é imperioso assinalar que ao presente estudo, o maior interesse se reflete a valorização do trabalho humano, a dignidade da pessoa humana, a função social da propriedade e a defesa do meio ambiente, levando-se em conta, especialmente, a amplitude a que se alcança o real significado de trabalho, sobretudo ao se considerar a proteção da saúde do trabalhador, direito crucial àquele que determina a produtividade, mas que também faz do trabalho um instrumento de realização e crescimento profissional.

\section{A COMPREENSÃO DE "TRABALHO": CONCEPÇÃO MATERIAL $X$ CONCEPÇÃO HUMANIZADA}

A atividade empresarial sofreu inúmeras e progressivas transformações que implicam diretamente na organização do trabalho, decorrentes das inovações tecnológicas, da alta competitividade, da globalização e do capitalismo exacerbado, cujas pretensões passaram a ser resumidas a busca pela produtividade e pela redução de custos e, consequentemente, pela persecução incessante pelo lucro.

Tais transformações refletem diretamente na compreensão a que se atribui ao trabalho enquanto instrumento de desenvolvimento, isso porque este passa a ser visualizado apenas como mecanismo de produção, cada vez mais pautado em lucro e redução de custos.

Como assinala Oliveira (2009, p. 147), “os avanços tecnológicos e, com eles, os procedimentos de automação, desconsideram o valor trabalho e prendem-se somente à produção e redução de custos com aumento de lucratividade”.

A partir disso, o homem passa a ser tratado como mercadoria destinada a mera produção, estando reduzido, assim, a uma concepção unicamente monetária, totalmente despersonalizada.

Nesse sentido é que se compõe a postura empresarial, que além de "coisificar" o trabalhador, compreende que para ele o trabalho é apenas um meio de sobrevivência, destinado a garantia das necessidades básicas do ser humano.

Por meio deste contexto é que se evidencia uma concepção material de trabalho, que circunda a ideia de uma empresa direcionada única e exclusivamente a produção de bens, em que se "pressupõe o homem como mera engrenagem, elemento descartável imerso no modo de produção, constituindo-se como que um acessório da produção” (OLIVEIRA, 2009, p. 139).

Há, assim, “o próprio esvaziamento da percepção da importância do trabalho na sociedade capitalista. [...] o trabalho somente interessaria como via instrumental de obtenção 
de outros bens, sendo desprovido de um valor próprio", conforme menciona Wandelli (2016, p. 1.019).

Ocorre que, não é nessa conjuntura que se enquadra o direito ao trabalho, na medida em que a Ordem Constitucional estabelece com clareza o significado e a amplitude que se deve atribuir ao trabalho, uma condição humana, social e fundamental.

O trabalho é que delineia a dignidade do trabalhador, não apenas pela garantia de subsistência, mas sim enquanto instrumento de realização, satisfação e valorização do ser humano, isso porque, nas palavras de Leonardo Vieira Wandelli (2016, p. 287-314), “o trabalho, como conjunto de atividades e relações, constitui-se em uma mediação essencial para autorrealização humana em termos de autonomia, saúde, ética e política".

Nesse sentido, verifica-se, inclusive, da Declaração referente aos fins e objetivos da Organização Internacional do Trabalho - Declaração de Filadélfia (1944), a afirmação de que “o trabalho não é mercadoria", constante no item I, alínea "a" e, ainda, no item III, alínea "b", a obrigação da OIT, em auxiliar as Nações do Mundo na execução de programas que visem "dar a cada trabalhador uma ocupação na qual ele tenha a satisfação de utilizar, plenamente, sua habilidade e seus conhecimentos e de contribuir para o bem geral”.

Dessa forma, a concepção humanizada é muito mais abrangente e completa em atenção ao real sentido a que se deve atribuir ao trabalho. Neste ponto, imperioso destacar os ensinamentos de Oliveira (2009, p. 147), segundo o qual a concepção da realidade que compreende o trabalho humano deve também principiar da noção do meio ambiente de trabalho, com a finalidade de se alcançar a efetivação de uma gestão responsável da atividade empresarial, no sentido de valorizar igualmente àquele que trabalha.

Neste contexto é que se visualiza a Ordem Econômica constitucionalmente construída, conforme assinala Wandelli (2016, p. 1.017) no sentido de que "ante o conjunto dos enunciados constitucionais não há como se conceber a dignidade da pessoa humana, como fundamento nuclear de todo ordenamento jurídico, de modo tal que não contemple a intensa vinculação com o trabalho enquanto dimensão essencial dessa dignidade”.

Há que se destacar que, o mesmo autor (2016, p. 1.019) retrata a diferença entre as duas concepções aqui abordadas, mencionando que "emerge a formulação de um desenho de nosso direito fundamental apto a resgatar a tensão entre trabalho vivo e força de trabalho subsumida ao capital, mesmo no interior das relações de trabalho existentes e no contexto normativo vigente".

É evidente, assim, que existe uma compreensão bastante equivocada sobre trabalho, isso porque só se pensa em subsistência, ao se falar de trabalhador, e, acumulação de riqueza, ao se 
falar em empregador, não havendo uma preocupação circundante ao conteúdo desse trabalho para o trabalhador, ou seja, o que ele reflete a sua vida além da sua própria sobrevivência em termos de remuneração.

Não se trata apenas de produção e obrigação, mas sim do que este trabalho proporciona ao individuo além da própria remuneração. Frise-se que não se quer dizer que a contraprestação ao trabalho desempenhado não é importante, mas sim que o trabalho, em todo seu conteúdo, é muito mais que isso.

Nesse panorama, é válido destacar as palavras de Wandelli (2016, p. 1.027):

\begin{abstract}
Em todas essas dimensões, o centro de sentido do direito ao trabalho está na compreensão de que aquele que trabalha tem, no trabalho, uma mediação essencial para a realização das necessidades humanas e para a construção da identidade, estabilização da saúde, construção de vínculos de solidariedade, e aprendizado ético e político. Por isso, o trabalhar, mesmo nas relações assalariadas, assim como nas formas não assalariadas de trabalho, não é apenas o se desincumbir, pelo trabalhador, da obrigação assumida pelo contrato com aquele que contratou seu trabalho. Mas é, ao mesmo tempo, nesse mesmo ato, o exercício de um direito fundamental cuja realização depende de condições que se referem ao conteúdo da atividade e da organização do trabalho, contrarrestando, juridicamente, o direito do empregador sobre essa mesma atividade e organização.
\end{abstract}

Assim, o trabalho não deve ser considerado apenas como produtor de resultados materiais ou como instrumento técnico de produção. Estas concepções são importantes e necessárias, inclusive para o desenvolvimento econômico do país. Contudo, não são suficientes para se estabelecer a identidade do trabalhador e concretizar a sua dignidade.

Ocorre que, o trabalhador na atualidade acaba por se submeter à lógica defendida pelo capital, e, segundo assinala Dutra (2012, p. 270) acaba por corromper sua própria personalidade e seus objetivos pessoais em detrimento da lógica de produção e os reais propósitos defendidos pela atividade empresarial, dissociando-se, assim, dos valores sociais que também compreendem a ordem econômica.

Dessa forma, verifica-se uma realidade estruturada em desacordo com a construção normativa da ordem econômica, que determina a primazia da valorização do trabalho humano, a fim de se garantir a dignidade do trabalhador.

A partir disso, verifica-se a necessidade "de uma mudança na concepção de ordem econômica, do resgate, na prática, daquilo que deve ser entendido por ordem econômica" (OLIVEIRA, 2009, p. 147).

Diante disso, deve-se compreender o real valor e sentido do trabalho humano, a fim de que se possa observar a realidade normativa da ordem econômica, transformando a concepção 
abstrata de trabalho em expressão de dignidade, liberdade e realização, preocupando-se com a própria essência do trabalhador.

\section{A PROTEÇÃO A SAÚdE dO TRABALHADOR ENQUANTO FUNDAMENTO A VALORIZAÇÃO DO TRABALHO HUMANO}

Ao se pensar em organização do trabalho, se ingressa na seara do meio ambiente em que o trabalhador está inserido, o qual possui tutela constitucional enquanto proteção a saúde do trabalhador.

O fundamento da previsão constitucional encontra alicerce especialmente na dignidade da pessoa humana e na valorização social do trabalho, consoante se destacam os artigos $1^{\circ}$, incisos III e IV, e 170 da Carta Magna, circundantes do Estado Democrático de Direito e da Ordem Econômica.

Visualiza-se, dessa forma, que o trabalho não está unicamente relacionado à produtividade e aos ganhos financeiros, mas também a sua valorização enquanto instrumento de satisfação e realização do indivíduo que o desempenha.

E para esta valorização, encontra-se com evidência a necessidade de proteção da saúde do trabalhador, através da garantia de um meio ambiente de trabalho seguro e saudável, ainda mais ao se considerar que é neste ambiente que o trabalhador passa a maior parte de sua vida.

Nesse sentido, verifica-se que a sua tutela está assegurada na norma constitucional, infraconstitucional e internacional, havendo um amplo arcabouço jurídico-normativo destinado a prevenção de acidentes de trabalho e moléstias ocupacionais incapacitantes.

A partir disso, "o objetivo maior é obrigar o empregador e tomador de serviços a cumprirem as normas de segurança e higiene e prevenir, efetivamente, o meio ambiente do trabalho dos riscos para a saúde dos trabalhadores” (MELO, 2013, p. 133).

A proteção constitucional especificamente do meio ambiente do trabalho se visualiza em seu artigo $7^{\circ}$, inciso XXII, o qual prevê que "a redução dos riscos inerentes ao trabalho por meio de normas de saúde, higiene e segurança" (BRASIL, 1988).

Igualmente na seara constitucional, verifica-se uma proteção ampliativa do meio ambiente em sua integralidade, através do seu artigo 225, o qual dispõe que "todos têm direito ao meio ambiente ecologicamente equilibrado, bem de uso comum do povo e essencial à sadia qualidade de vida, impondo-se ao Poder Público e à coletividade o dever de defendê-lo e preservá-lo para as presentes e futuras gerações” (BRASIL, 1988). 
Por sua vez, em sede infraconstitucional, a proteção específica do meio ambiente do trabalho encontra guarida na Consolidação das Leis do Trabalho, a qual contém uma previsão legal preventiva e incumbe, ainda, ao órgão competente, a criação de normas atinentes a segurança e medicina do trabalho, que são as chamadas Normas Regulamentadoras, instrumentalizadas pela Portaria 3.214/78.

A Organização Internacional do Trabalho, por seu turno, também contempla uma ampla normatização, especialmente através de suas Convenções, das quais, em tema de saúde e segurança do trabalho, destacam-se as de $\mathrm{n}^{\circ} 155$ e 161.

A primeira determina aos Estados-Membros a concepção de uma Política Nacional em termos de Saúde, Segurança e Meio Ambiente de Trabalho, voltada aos trabalhadores de todas as atividades econômicas, tendo por objetivo "prevenir os acidentes e os danos à saúde que forem consequência do trabalho, tenham relação com a atividade de trabalho, ou se apresentarem durante o trabalho, reduzindo ao mínimo, na medida em que for razoável e possível, as causas dos riscos inerentes ao meio ambiente de trabalho" (OIT, 1992).

A Convenção 161, da mesma forma, apresenta um conjunto normativo de caráter prevencionista e é relativa, especialmente, aos "Serviços de Saúde no Trabalho" (OIT, 1988), em uma concepção de aconselhamento de trabalhadores e empregadores, ressaltando a importância do próprio trabalhador em relação ao conhecimento de riscos a que está exposto, assim como as adequações que se demonstram necessárias.

É importante destacar, sob esta perspectiva, a imprescindibilidade de atos de prevenção na proteção da saúde do trabalhador, isso porque, através deles, se alcança a tutela da vida e da dignidade dos trabalhadores, que se estabelecem como alicerces do Estado Democrático de Direito e da Ordem Econômica, sobretudo sob a ótica do valor social do trabalho e da proteção do meio ambiente de trabalho (MELO, 2013, p. 135).

Há que se pontuar também que é mediante a prevenção que se torna possível a construção de um meio ambiente marcado por condições adequadas de trabalho e digno de promover uma sadia qualidade de vida. O meio ambiente de trabalho deve ser observado enquanto espaço de exercício do direito a dignidade e, por isso, preservado de forma a assegurar proteção a vida e a saúde do trabalhador (CAMPELLO E CAMPOS NETO, 2013, p. 176).

Dessa forma, em respeito ao valor social do trabalho, a dignidade da pessoa humana e ao meio ambiente, é que se fundamenta o direito a proteção da saúde do trabalhador, direito fundamental para que ele possa desenvolver o seu trabalho e, através dele, se realizar e construir sua identidade.

Vale destacar aqui que, 
ambiente de trabalho é tudo o que condiciona a produção do trabalho, desde o local onde o trabalho é realizado, a forma de prover o necessário para que ele se desenvolva, o equilíbrio que deve ser buscado com os meios colocados à disposição do trabalhador para que este produza, devendo o mesmo assegurar a condições necessárias para uma condição de vida digna. Trata-se da quebra do conceito que mercadologicamente vem sendo tratando como trabalho. (OLIVEIRA, 2009, p. 143)

Nesse sentido, é com evidência que, se a postura empresarial não for condizente com a proteção do meio ambiente e, em consequência, da saúde do trabalhador, o resultado serãoO acidentes de trabalho e doenças ocupacionais, os quais, na maioria dos casos, implicam em afastamentos, o que culmina na perda do real e determinante significado de trabalho para àqueles que forem atingidos. Este é o reflexo de uma ordem econômica desconectada do valor social e humano do trabalho.

Neste aspecto, cumpre mencionar que, não havendo repressão, a prevalência se direciona ao pensamento econômico, isso porque o meio ambiente de trabalho, ao invés de ser visualizado também sob o aspecto da saúde e segurança dos trabalhadores, se restringe ao olhar da produtividade, tornando-se, assim, propulsor de doenças ocupacionais e acidentes de trabalho (MELO, 2006, p. 43).

A atuação empresarial despreocupada com a prevenção e indiferente em relação a provocação de danos aos trabalhadores frente a inadequação de seu ambiente de trabalho implica a própria ausência de efetividade do complexo normativo existente, calcado na valorização do trabalhador enquanto agente essencial ao desenvolvimento da sociedade.

Como bem coloca Renata Queiroz Dutra, referenciando Cristophe Dejours (DEJOURS apud DUTRA, 2012, p. 261), "a reformulação das relações sociais, com a atribuição de uma condição precária ao trabalho, o coloca como fonte de sofrimento, numa deturpação da afirmação identitária, da qual ele continua a ser principal mediador”.

Observa-se, assim, que é necessária a estruturação da responsabilidade empresarial, não àquela atinente a reparação de danos, mas sim uma responsabilidade preventiva e consciente, preocupada com a gestão adequada da sua atividade, com a valoração daqueles que determinam o seu crescimento e desenvolvimento na economia, sem se resguardar única e exclusivamente a concepção técnica e material de sua atividade.

Assim, conforme preleciona Oliveira (2009, p. 148), "na ordem econômica, o trabalho não pode ser simplificado e reduzido a expressões monetárias, fazendo do homem trabalhador uma mera engrenagem da produção". 
Destaque-se que o seu reconhecimento não se limita ao fato de perceber uma remuneração, até porque, ainda que esta seja garantia de dignidade, não transcende a maior importância, até porque, de que adianta percebê-la e encontrar-se adoentado em virtude das condições a que se encontrava submetido no meio ambiente de trabalho.

O trabalho humanamente valorizado deve ser pautado na personalização do ser humano, que não deve ser considerado apenas mais um trabalhador, mais um instrumento de produção, e sim um indivíduo responsável e comprometido, que utiliza do trabalho como um meio de desenvolvimento de suas capacidades, de sua identidade e de sua dignidade.

Dessa forma, a proteção do meio ambiente de trabalho e, consequentemente, da saúde do trabalhador, destinada a preservação de sua integridade física e mental, se revela imprescindível a estruturação da ordem econômica constitucionalmente construída, preocupada com o real sentido do trabalho de todos aqueles que fazem parte de sua organização e, portanto, essencialmente compatível e fundamentada na valorização do trabalho humano.

\section{CONSIDERAÇÕES FINAIS}

O cenário progressivo da atividade empresarial é marcado cada vez mais pelo objetivo de aumento da produtividade e do lucro, sendo desconsiderados os efeitos que podem causar sobre a vida dos trabalhadores.

Em verdade, visualiza-se que a concepção de trabalho encontra-se direcionada ao alcance de resultados financeiros, como se fosse exclusivamente um instrumento técnico de produção em benefício das organizações.

Ocorre que, embora o trabalho seja fundamental ao desenvolvimento econômico do país, também é de grande relevância ao desenvolvimento social, ou seja, não basta que o trabalhador perceba uma remuneração pelos serviços prestados, mas que também, através dele, construa sua identidade, conquiste sua satisfação e proveja sua dignidade.

E, para isso, um dos mais importantes e necessários fatores a atingir este objetivo encontra-se inserido na saúde e integridade física e psíquica do trabalhador, o que se consuma através da garantia de um meio ambiente de trabalho seguro e saudável, capaz de preservá-lo de eventuais riscos capazes de resultar em acidentes de trabalho e doenças ocupacionais.

Nesse sentido é que se torna possível a construção da Ordem Econômica na forma prevista constitucionalmente, fundamentada na valorização do trabalho humano enquanto alicerce legitimador do exercício da livre iniciativa. 
Para tanto, é imprescindível que o trabalho não fique exclusivamente subsumido a aspectos financeiros, mas que esteja inserido na subjetividade do trabalhador através de seu conteúdo, que se vincula largamente a expressão da dignidade da pessoa humana, na construção de uma concepção humana e imaterial.

Dessa forma, é evidente que o trabalho legitima a construção da ordem econômica, desde que humanamente valorizado, o que determina a necessidade de proteção à saúde do trabalhador a fim de se garantir o alcance de sua essência, circundante pela dignidade da pessoa humana.

\section{REFERÊNCIAS}

BARROSO, Luís Roberto. A Ordem Econômica Constitucional e os limites à atuação estatal no controle de preços. Revista de Direito Administrativo, Rio de Janeiro, n. 226, p. 187-2012, out./dez. 2001. Disponível em: http://bibliotecadigital.fgv.br/ojs/index.php/rda/article/view/47240. Acesso em: 28 dez. 2019

BRASIL. Constituição Federal de 1988. Constituicão da República Federativa do Brasil. Disponível em: http://www.planalto.gov.br/ccivil_03/decreto-lei/Del2848compilado.htm. Acesso em: 20 nov. 2018

BRAZ, Viviane Alline Gregorio Azevedo. O trabalhador entre a saúde e a (in)segurança do trabalho. Revista da Faculdade de Serviço Social da Universidade do Estado do Rio de Janeiro, Rio de Janeiro, n. 32, v. 11, p. 273-295, 2013. Disponível em: https://www.epublicacoes.uerj.br/index.php/revistaempauta/article/view/10166. Acesso em: 04 jan. 2020

CAMPELLO, Lívia Gaigher Bósio; CAMPOS NETO, Carlos Walter Marinho. Tutela do Meio Ambiente do Trabalho nos planos internacional e interno. Revista de Direito Argumentum, n. $14, \quad$ p. 167-185, 2013. Disponível em: http://ojs.unimar.br/index.php/revistaargumentum/article/view/982/0. Acesso em: 10 jan. 2020

DEJOURS, 2006 apud DUTRA, Renata Queiroz. Direitos Fundamentais Sociais à afirmação da identidade e à proteção da subjetividade no trabalho. Revista do Tribunal Superior do Trabalho, Brasília, v. 78, n. 4, out./dez 2012. Disponível em: https://juslaboris.tst.jus.br/handle/20.500.12178/35839. Acesso em: 04 jan. 2020

DUTRA, Renata Queiroz. Direitos Fundamentais Sociais à afirmação da identidade e à proteção da subjetividade no trabalho. Revista do Tribunal Superior do Trabalho, Brasília, v. 78, n. 4, out./dez 2012. Disponível em: https://juslaboris.tst.jus.br/handle/20.500.12178/35839.

Acesso em: 04 jan. 2020

GOMES, Carlos Jacques Vieira. O Princípio Constitucional da Livre Concorrência: corolário da livre iniciativa ou princípio autônomo da ordem econômica?. In: Senado Federal, Constituição de 1988: O Brasil 20 anos depois - Estado e Economia em vinte anos de mudanças, Brasília, v. IV, 2013. Disponível em: https://www12.senado.leg.br/publicacoes/estudos-legislativos/tipos-de-estudos/outras- 
publicacoes/volume-iv-constituicao-de-1988-o-brasil-20-anos-depois.-estado-e-economia-emvinte-anos-de-mudancas/principios-gerais-da-ordem-economica-o-principio-constitucionalda-livre-concorrencia-corolario-da-livre-iniciativa-ou-principio-autonomo-da-ordemeconomica. Acesso em: 28 dez. 2019

MELO, Raimundo Simão de. Direito ambiental do trabalho e a saúde do trabalhador. 2. ed., São Paulo: LTr, p. 43, 2006

MELO, Raimundo Simão de. Meio Ambiente do Trabalho e Atividades de Risco: Prevenção e Responsabilidades. Revista do Tribunal Regional do Trabalho da $9^{\mathbf{a}}$ Região, Curitiba, p. 131-152, outubro 2013. Disponível em: http://www.mflip.com.br/pub/escolajudicial/?numero=23\&edicao=2372\#page/8. Acesso em: 14 out. 2019

OLIVEIRA, Lourival José de. A responsabilidade do Estado e da empresa na construção do meio ambiente do trabalho diante da nova realidade econômica. Revista de Direito Argumentum, n. 10, p. 137-158, 2009. Disponível em:

http://ojs.unimar.br/index.php/revistaargumentum/article/view/1037. Acesso em: 10 jan. 2020

ORGANIZAÇÃO INTERNACIONAL DO TRABALHO. Constituição da Organização Internacional do Trabalho (OIT) e seu anexo (Declaração de Filadélfia). Declaração referente aos fins e objetivos da Organização Internacional do Trabalho. Disponível em: https://www.ilo.org/brasilia/conheca-a-oit/WCMS_336957/lang--pt/index.htm Acesso em: 02 dez. 2019

ORGANIZAÇÃO INTERNACIONAL DO TRABALHO. Convenção 155. Disponível em: <http://www.ilo.org/brasilia/convencoes/WCMS_236163/lang--pt/index.htm> Acesso em: 21 maio 2019

ORGANIZAÇÃO INTERNACIONAL DO TRABALHO. Convenção 161. Disponível em: <http://www.ilo.org/brasilia/convencoes/WCMS_236240/lang--pt/index.htm> Acesso em: 21 maio 2019

PEIXOTO, Leonardo Jose; MAIA, Cinthia Moneses. A FUNÇÃO SOCIAL DA EMPRESA COMO FORMA DE PROTEÇÃO AO EMPREGADO. Revista Juridica, [S.1.], v. 1, n. 54, p. 193 - 212, mar. 2019. ISSN 2316-753X. Disponível em: <http://revista.unicuritiba.edu.br/index.php/RevJur/article/view/3306/371371799>. Acesso em: 17 abr. 2020. doi:http://dx.doi.org/10.21902/revistajur.2316-753X.v1i54.3306.

SOUZA FREIRE PIMENTA, Adriana Campos de; PRATA, Lucília Alcione. O tratamento da questão econômica na história constitucional brasileira. Revista do Tribunal Regional do Trabalho da $3^{\text {a }}$ Região, Belo Horizonte, v. 50, n. 180, p. 227-254, jul./dez. 2009. Disponível em:

https://juslaboris.tst.jus.br/bitstream/handle/20.500.12178/74334/2009_pimenta_adriana_trata mento_questao.pdf?sequence=1\&isAllowed=y. Acesso em: 04 jan. 2020

WANDELLI, Leonardo Vieira. Da Psicodinâmica do trabalho ao direito fundamental ao conteúdo do próprio trabalho e ao meio ambiente organizacional saudável. In: MACÊDO, Katia 
Barbosa et al (Org). Organização do Trabalho e Adoecimento: uma visão interdisciplinar. Goiânia: PUC GOIÁS, 2016, p. 287-314.

WANDELLI, Leonardo Vieira. O Direito Fundamental ao Conteúdo do próprio Trabalho: uma reconstrução normativa do direito ao trabalho. Espaço Jurídico Journal of Law, Joaçaba, v. 17, n. 3, p. 1013-1036, set./dez. 2016. Disponível em: https://portalperiodicos.unoesc.edu.br/index.php/espacojuridico/article/view/10199. Acesso em: 05 jan. 2020 